\title{
A CONSTRUÇÃO DA ESCOLA DE TEMPO INTEGRAL: RELAÇões ENTRE AS OPÇões POĹtICO-PEDAGógICAS DA SECRETARIA DE EDUCAÇÃO (MACRO) E DA ESCOLA (MICRO)
}

\begin{tabular}{c}
\hline THE CONSTRUCTION OF THE FULL-TIME SCHOOL: \\
RELATIONS BETWEEN POLITICAL AND PEDAGOGICAL OPTIONS OF THE EDUCATION \\
DEPARTMENT (MACRO) AND THE SCHOOL (MICRO) \\
LA CONSTRUCCIÓN DE LA ESCUELA DE TIEMPO COMPLETO: \\
RELACIONES ENTRE LAS OPCIONES POLÍTICO-PEDAGÓGICAS DE LA SECRETARIA DE \\
EDUCACIÓN (MACRO) Y DE LA ESCUELA (MICRO)
\end{tabular}

Cláudia da Mota Darós Parente 1

\begin{abstract}
RESUMO: O presente artigo tem como objetivo analisar o processo de construção de uma escola de tempo integral, sistematizando as relações entre as opções político-pedagógicas definidas no âmbito da Secretaria Municipal de Educação (macro) e as opções político-pedagógicas definidas no âmbito da escola (micro). $\mathrm{O}$ artigo é resultado da parceria com uma escola pública do interior de São Paulo e as informações foram coletadas por meio de observações das oficinas de enriquecimento curricular desenvolvidas no contraturno, reuniões com a equipe gestora e grupos de discussão/formação com professores e gestores durante o horário de estudo coletivo. $\mathrm{O}$ artigo traz evidências acerca da multidirecionalidade da política pública, destacando que a escola e seus sujeitos não devem ser vistos como meros executores da política pública; são também, em certa medida, (re)formuladores da política pública.
\end{abstract}

PALAVRAS-ChaVE: Escola de Tempo Integral. Política Educacional. Processo Decisório.

ABSTRACT: The purpose of this article is to analyze the process of building a full-time school, systematizing the relations between the political and pedagogical options defined in the scope of the Municipal Education Department (macro) and the political and pedagogical options defined within the school (micro). The article is a result of the partnership with a public school in the countryside of state of São Paulo, and the information was collected through observations of the curriculum enrichment workshops developed during the school day, meetings with the management team and discussion/training groups with teachers and managers during the collective study hours. The article brings evidences about the multidirectionality of the public policy, emphasizing that the school and its subjects should not be seen as simple executors of the public policy; they are also, to a certain extent, (re)formulators of the public policy.

KEYWORDS: Full-time school. Educational policy. Decision-making process.

RESUMEN: El presente artículo tiene como objetivo analizar el proceso de construcción de una escuela de tiempo completo, sistematizando las relaciones entre las opciones político-pedagógicas definidas en el ámbito de la Secretaría Municipal de Educación (macro) y las opciones político-pedagógicas definidas en el ámbito de la escuela (micro). El artículo es resultado de la asociación con una escuela pública del interior de São Paulo y las informaciones fueron recolectadas por medio de observaciones de los talleres de enriquecimiento curricular desarrollados durante la jornada escolar diaria, reuniones con el equipo gestor y grupos de discusión/formación con profesores y gestores durante el horario de estudio colectivo. El artículo trae evidencias acerca de la

Submetido em: 30/04/2018 - Aceito em: 15/05/2018 - Publicado em: 20/11/2018

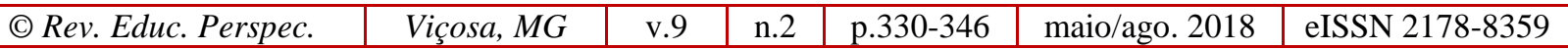


multidireccionalidad de la política pública, destacando que la escuela y sus sujetos no deben ser vistos como meros ejecutores de la política pública; son también, en cierta medida, (re)formuladores de la política pública.

PALABRAS ClAVE: Escuela a tiempo completo. Política educacional. Proceso decisorio.

\section{INTRODUÇÃO}

No atual contexto de formulação e implementação de políticas educacionais, entre as várias demandas expressas no Plano Nacional de Educação (PNE), aprovado em 2014, está a meta 6 relativa à ampliação da educação em tempo integral (BRASIL, 2014). O fato é que muitas políticas formuladas e implementadas após a aprovação do PNE (e seus similares - Planos Estaduais e Municipais de Educação) condicionarão a cultura da escola e seus projetos educativos. Ou seja, muitas escolas com jornada parcial podem vir a ter uma jornada integral. $\mathrm{E}$ isso pode ser feito com base em diferentes argumentos, com ou sem as devidas condições materiais necessárias, com ou sem a consulta aos diferentes atores envolvidos nos processos educativos. Por sua vez, no momento da implementação, as condições materiais, físicas, humanas, administrativas e políticas, e mesmo os valores e as concepções dos diferentes atores implementadores, condicionarão a política pública de educação em tempo integral. Esses elementos são aspectos relevantes para uma análise mais aprofundada do processo de decisão política na área da educação.

A partir desses apontamentos iniciais questiona-se: diante de uma política de educação integral em tempo integral, como se constrói uma escola de tempo integral? O presente artigo tem como objetivo analisar o processo de construção de uma escola de tempo integral, sistematizando as relações entre as opções político-pedagógicas definidas no âmbito da Secretaria Municipal de Educação (macro) e as opções político-pedagógicas definidas no âmbito da escola (micro).

O artigo é resultado de análises produzidas a partir da parceria realizada com uma escola pública municipal do interior de São Paulo ${ }^{i}$. As informações contidas no presente artigo foram coletadas por meio de: 1) Observações das oficinas de enriquecimento curricular desenvolvidas pela escola no contraturno; 2) Pesquisa documental ${ }^{\mathrm{ii}}$; 3) Reuniões periódicas com a equipe gestora da escola ( 2 coordenadores, 1 diretor e 1 vice-diretor); 4) Grupos de discussão/formação (20 professores, 2 coordenadores, 1 diretor e 1 vice-diretor) durante o horário de estudo coletivo ${ }^{\mathrm{iii}}$; 5) Questionário aplicado a 16 professores. As informações coletadas durante as observações das oficinas, as reuniões com os gestores e os grupos de discussão/formação foram registradas em diários de campo ${ }^{\text {iv }}$.

A análise terá como referencial teórico, principalmente, os estudos de Lindblon (1981) sobre o processo de decisão política, Lima (2011) sobre a cultura e a organização da escola e

\begin{tabular}{l|c|c|c|c|c|c} 
(C) Rev. Educ. Perspec. & Viçosa, $M G$ & v.9 & n.2 & p.330-346 & maio/ago. 2018 & eISSN 2178-8359 \\
\hline
\end{tabular}


Parente (2016) sobre as tipologias das políticas de educação integral em tempo integral. Os dados coletados, analisados à luz do referencial teórico, possibilitaram sistematizar elementos para compreender como ocorre o processo de construção de uma escola de tempo integral e as relações estabelecidas nos âmbitos macro e micro do sistema educativo.

\section{POLÍTICA DE EDUCAÇÃO EM TEMPO INTEGRAL E ESCOLA DE TEMPO INTEGRAL: CONTEXTUALIZANDO O CENÁRIO DE FORMULAÇÃO E IMPLEMENTAÇÃ̃O DA POLÍTICA}

A escola de tempo integral em análise está situada num município do interior de São Paulo. O respectivo município iniciou sua política de educação em tempo integral, em 2014, em apenas uma escola da rede municipal. Em 2015, iniciou suas atividades numa segunda escola; em 2016, em mais duas escolas; em 2017, na quinta escola.

Em termos legais, no Brasil, a jornada é considerada em tempo integral quando possui "[...] duração igual ou superior a sete horas diárias, durante todo o período letivo, compreendendo o tempo total que um mesmo aluno permanece na escola ou em atividades escolares [...]" (BRASIL, 2007). Diante dessa determinação nacional, a legislação municipal estabeleceu que a escola de tempo integral tenha uma jornada de 8 (oito) horas diárias, sendo o turno da manhã destinado aos conteúdos das áreas de conhecimento da "base nacional comum" conforme prevê a Lei de Diretrizes e Bases da Educação Nacional - LDB (BRASIL, 1996, art. 36) - e o turno da tarde destinado às atividades de enriquecimento curricular, por meio de oficinas. Entre as temáticas a serem abordadas nas oficinas, de acordo com a legislação municipal, estão: orientação de estudos; atividades artísticas, esportivas e motoras; jogos educativos; atividades de leitura; atividades relacionadas à qualidade de vida e à área de direitos humanos; inglês; informática.

Em consonância com os artigos 61 e 62 da LDB (BRASIL, 1996), a legislação municipal define ainda que as oficinas, em geral, deverão ser de responsabilidade de profissionais com formação em Pedagogia. Algumas oficinas específicas (a exemplo das oficinas de inglês e daquelas relacionadas a atividades esportivas e motoras) serão de responsabilidade de profissionais licenciados (a exemplo dos profissionais licenciados em Letras e Educação Física). Há também previsão de coordenador pedagógico para as oficinas, ou seja, para coordenação das atividades de contraturno.

Levando-se em consideração a legislação municipal que define as atividades de enriquecimento curricular, a escola parceira, no período da manhã, desenvolve o chamado currículo "regular" e, no período da tarde, desenvolve 10 oficinas: Produção de Textos, Estratégias de Leitura, Jogos Ortográficos, Jogos Matemáticos, Informática Educativa,

\begin{tabular}{l|c|c|c|c|c|c} 
(C) Rev. Educ. Perspec. & Viçosa, $M G$ & v.9 & n.2 & p.330-346 & maio/ago. 2018 & eISSN 2178-8359 \\
\hline
\end{tabular}


Língua Inglesa, Atividades Recreativas, Atividades Artísticas, Saúde e Meio Ambiente, Direitos Humanos e Sociedade.

A escola parceira possui cerca de 220 alunos, com idade entre 6 e 11 anos, matriculados no primeiro segmento do ensino fundamental $\left(1^{\circ}\right.$ ao $5^{\circ}$ ano). Os estudantes cumprem a jornada em tempo integral no período compreendido entre $7 \mathrm{~h} 30$ e $16 \mathrm{~h} 30$. Todos os alunos da escola estudam em período integral. São oferecidas três refeições diárias: às 9h (lanche), às 11h30 (almoço) e às $14 \mathrm{~h}$ (lanche).

A escola parceira possui, entre outros espaços, quadra poliesportiva, quadra interna, pátio interno, área de refeitório, 10 salas de aula, sala de recursos, sala de leitura, laboratório de informática, sala de vídeo.

Diante dos elementos descritos, deseja-se analisar o processo de construção desta escola que possui jornada escolar em tempo integral, sistematizando as relações entre as opções políticopedagógicas definidas no âmbito da Secretaria Municipal de Educação (macro) e as opções político-pedagógicas definidas no âmbito da escola (micro).

\section{RELAÇÕES ENTRE AS OPÇÕES POLÍTICO-PEDAGÓGICAS NOS ÂMBITOS MACRO E MICRO: CONSTRUINDO A ESCOLA DE TEMPO INTEGRAL}

Neste trabalho, a política pública é compreendida como o "Estado em Ação" (GOBERT; MULLER, 1987 apud HÖFLING, 2001, p. 31). No que se refere à temática da educação integral em tempo integral, em meio às determinações legais produzidas nos últimos anos (BRASIL, 1996; 2007; 2014), vários estados e municípios iniciaram um processo de formulação e implementação de políticas de educação em tempo integral.

No caso da formulação de políticas, conforme Lindblon (1981, p. 39), “[...] os formuladores de políticas ativos [...] dado o controle que exercem sobre o processo de decisão política, são uma elite, composta de autoridades executivas [...]", entre outras autoridades do legislativo e do judiciário. Dias e Matos (2012, p. 43), reforçam essa posição afirmando que os atores públicos, entre eles, os gestores públicos, são os que possuem “[...] a faculdade de poder decidir políticas", e, portanto, é preciso entender os limites que existem na configuração de políticas que atendam os anseios e as necessidades dos vários atores envolvidos nas questões educacionais.

No entanto, apesar de compreender que são justamente os órgãos gestores dos sistemas de ensino e seus representantes os responsáveis pela formulação da política pública na área de

\begin{tabular}{l|c|c|c|c|c|c} 
(C) Rev. Educ. Perspec. & Viçosa, $M G$ & v.9 & n.2 & p.330-346 & maio/ago. 2018 & eISSN 2178-8359 \\
\hline
\end{tabular}


educação, defende-se que a escola é também locus de importantes decisões, cujos sujeitos, repletos de intencionalidades e concepções, são também atores que interferem na política pública, seja para legitimá-la, seja para resistir a ela. Isso porque, acredita-se, que não existe uma unidirecionalidade entre formulação e implementação. A implementação da política pública não é o resultado direto do que foi formulado. Além disso, defende-se que a política é feita por "[...] atores concretos que entram em relação entre si (enfrentando-se quando necessário) por ocasião de sua elaboração ou de sua implementação" (MULLER, 1990 apud DRAIBE, 1991, p. 16).

É com essa concepção de política pública que se busca compreender como uma escola inicia seu funcionamento em tempo integral e como as opções político-pedagógicas de seus órgãos superiores, no caso, a Secretaria Municipal de Educação, se coadunam (ou não) com as opções político-pedagógicas da escola.

Para compreender as relações entre as opções político-pedagógicas da escola parceira e os direcionamentos da Secretaria Municipal de Educação, primeiramente foram analisados os documentos legais que evidenciam o surgimento da escola de tempo integral no respectivo município e que apontam suas prescrições em termos de política pública, conforme descrito na seção anterior. Por meio de lei aprovada na Câmara Municipal, o município instituiu seu projeto de escolas de tempo integral com o objetivo principal de ampliar as possibilidades de aprendizagem e de enriquecer o currículo das escolas. Além da análise documental, por meio do acompanhamento das oficinas de enriquecimento curricular, foi possível ver a política em processo de implementação no âmbito da escola. Por fim, foram coletadas informações junto à equipe escolar durante os espaços formativos (reuniões e grupo de discussão) e por meio do questionário aplicado aos professores.

Em Parente (2016) é possível visualizar os principais elementos que vêm norteando as políticas de educação integral em tempo integral. O estudo apresenta uma tipologia na qual categoriza e caracteriza 24 tipos de políticas na área. Esse exercício possibilitou a visualização das opções político-pedagógicas que os diferentes entes federativos vêm desenvolvendo em termos de educação integral em tempo integral recentemente no Brasil. Essas opções condicionam muitas das ações a serem desenvolvidas no âmbito da escola.

Diante dos elementos descritos inicialmente e com base nas classificações estabelecidas em Parente (2016), pode-se inferir que, em termos de opções político-pedagógicas, a Secretaria Municipal de Educação em análise formulou e implementou políticas de educação em tempo integral parciais, atendendo apenas parte das escolas da rede; em sua maioria, são políticas restritas ao espaço escolar; são políticas que contam com diferentes profissionais da educação, embora com ênfase nos profissionais efetivos; por fim, são políticas formuladas e 
implementadas apenas no âmbito do município, sem relação direta com outros entes federativos ${ }^{\mathrm{v}}$.

Assim, diante da configuração da política de educação em tempo integral formulada no município em análise, seria ingênuo acreditar que seu processo de implementação na escola ocorreu tal qual foi prescrito legalmente e previsto pelos gestores da Secretaria de Educação.

Isto porque, a forma como a escola se organiza, sua função sócio-histórica e cultural, seus determinantes e suas repercussões na sociedade são elementos de grande relevância para a compreensão de como as políticas educacionais são implementadas pelas instituições educativas. A escola e sua equipe não podem ser entendidas como meros executores da política pública. Não é à toa que as políticas, quando implementadas, não são simples traduções de sua fase de formulação. A concepção de política pública presente neste artigo busca superar o hiato entre formulação e implementação, dando novas concepções acerca de como a política é implementada. A escola e seus integrantes são detentores de valores e de intencionalidades que formam o que Forquin (1993) denominou "cultura da escola".

Na visão de Nóvoa (1999, p. 16), a organização escolar é rica em produções, articulações e concepções; constitui-se numa "[...] territorialidade espacial e cultural, onde se exprime o jogo dos actores educativos internos e externos [...]”.

Por isso, pode-se afirmar que há uma multiplicidade de fatores que interferem na organização da instituição escolar e na construção de sua função. De acordo com Petitat (1994), há um elemento de contradição intrínseco à escola: ao mesmo tempo em que reproduz, também pode transformar.

Para além das definições no âmbito macro, há muito movimento no âmbito micro, por trás das definições que a escola faz em termos de equipe, de gestão, de currículo, de espaços, de organização de salas, horários, oficinas etc. A cultura da escola ao mesmo tempo em que é condicionada, também condiciona. As definições feitas no âmbito da Secretaria de Educação condicionam as opções político-pedagógicas da escola; por sua vez, as interações que acontecem no âmbito da escola em termos administrativos, pedagógicos, políticos, humanos e comunitários também condicionam o projeto de escola e, portanto, a política pública. Ou seja, há muito a se definir após tantas definições. A cultura de uma escola continua em movimento após esse conjunto de definições. Há muitas indefinições que vão sendo definidas à medida que o fazer pedagógico vai se materializando. E nesse processo de materialização do fazerpedagógico, o planejamento contínuo é parte fundamental. O planejamento pedagógico deve sempre partir de um processo de avaliação do que já foi realizado, dos possíveis avanços, dos erros cometidos, dos desafios que permaneceram, das dificuldades enfrentadas, dos desejos e das intencionalidades de seus sujeitos. É preciso, portanto, compreender a

\begin{tabular}{l|c|c|c|c|c|c|} 
(C) Rev. Educ. Perspec. & Viçosa, $M G$ & v.9 & n.2 & p.330-346 & maio/ago. 2018 & eISSN 2178-8359 \\
\hline
\end{tabular}


multidirecionalidade e a multidimensionalidade que existe no processo de planejamento e de organização do trabalho pedagógico numa escola de tempo integral (assim como em qualquer outra escola).

De acordo com Lima (2011, p. 114-115), “[...] a força da imposição normativa nem sempre é obedecida, ou traduzida em poder e em ações orientadas em conformidade”. O autor complementa que a escola é "[...] uma instância auto-organizada para a produção de orientações e de regras, expressão das capacidades estratégicas dos atores e do exercício (político) [...]".

Infere-se, assim, que a política pública produz interferências na cultura da escola; por sua vez, a cultura da escola interfere na forma como a política pública é implementada. Acreditase, portanto, na existência de uma multidirecionalidade na implementação das políticas públicas.

[...] as políticas educacionais produzem efeitos, condicionando o rumo da organização escolar [...]. No entanto, a escola, entendida como instituição muito mais versátil do que o mero reflexo das determinações e ações políticas, constrói seus próprios valores e concepções, capazes de conservar lógicas de longas datas, de impulsionar ações políticas, de transgredir normas legais e sociais, de inovar em face das condições estruturais e conceituais vigentes (PARENTE, 2006, p. 6).

Além disso, as determinações legais, provenientes dos órgãos gestores, não explicitam tudo que deve ocorrer no âmbito da escola. De acordo com Silva e Melo (2000, p. 9),

\begin{abstract}
a implementação é entendida como processo autônomo onde decisões cruciais são tomadas e não só "implementadas". [...] A implementação, portanto, 'cria' políticas: a implementação de políticas constantemente orienta novas políticas. Como a implementação implica em tomada de decisões, ela própria se constitui em fonte de informações para a formulação de políticas.
\end{abstract}

Reforça-se, assim, a concepção aqui defendida: a escola e seus sujeitos não devem ser vistos como meros executores da política pública. Do ponto de vista legal, a própria LDB e o PNE fazem indicações sobre as atribuições e as responsabilidades nos âmbitos macro e micro dos sistemas educativos.

Conforme a LDB, cabe aos municípios, entre outras atribuições

I - organizar, manter e desenvolver os órgãos e instituições oficiais dos seus sistemas de ensino, integrando-os às políticas e planos educacionais da União e dos Estados; [...] III - baixar normas complementares para o seu sistema de ensino; [...] (BRASIL, 1996, art. 11).

Por sua vez, conforme o PNE, cabe aos municípios, entre outras responsabilidades, elaborar seu próprio plano de educação (BRASIL, 2014, art. $8^{\circ}$ ).

\begin{tabular}{l|c|c|c|c|c|c} 
(C) Rev. Educ. Perspec. & Viçosa, $M G$ & v.9 & n.2 & p.330-346 & maio/ago. 2018 & eISSN 2178-8359 \\
\hline
\end{tabular}


No caso das escolas, entre outras incumbências, devem "elaborar e executar sua proposta pedagógica" (BRASIL, 1996, art. 12). Para isso, a LDB determina que "os sistemas de ensino assegurarão às unidades escolares públicas de educação básica que os integram progressivos graus de autonomia pedagógica e administrativa e de gestão financeira" (BRASIL, 1996, art. 12).

Assim, a formulação de uma política municipal de educação em tempo integral, em última instância, é de responsabilidade da Secretaria de Educação. Porém, é importante que seus gestores considerem, por um lado, o envolvimento de diferentes atores no processo de formulação da própria política e, por outro, deixem margem significativa de autonomia às escolas para que seus respectivos projetos educativos sejam elaborados com base nas necessidades e intencionalidades da comunidade escolar.

No caso da escola parceira, conforme relato dos gestores, a opção por funcionar em tempo integral foi uma demanda da própria escola e não da Secretaria de Educação, o que exemplifica a multidirecionalidade das políticas públicas, ainda que o Executivo tenha o papel decisivo no processo de decisão política.

O fato é que a demanda da escola (não há evidências, no entanto, de que tenha sido uma demanda definida coletiva e democraticamente) foi acatada pelos gestores da Secretaria de Educação e a escola passou a funcionar em tempo integral. Ressalta-se que a demanda criada pela escola ou por seus gestores demarca opções político-pedagógicas que interferem na própria configuração da política pública. Ou seja, deseja-se mostrar que, a depender das aproximações e/ou distanciamentos entre opções político-pedagógicas macro e micro, haverá consequências para os processos de aceitação e/ou rejeição de determinados atores a políticas comumente denominadas "de cima para baixo". No âmbito micro, se as opções políticopedagógicas dos diferentes atores também destoarem, ou seja, se a demanda for exclusiva da direção da escola e não de toda a comunidade escolar, isso terá consequências em termos de aceitação e de possíveis resistências internas.

No que se refere à opção político-pedagógica do sistema de ensino de ampliar a jornada escolar, conforme os estudos de Parente (2016), em termos de argumentos da política pública, existem: "políticas de educação integral em tempo integral sustentadas por argumentos pedagógicos" e "políticas de educação integral em tempo integral sustentadas por argumentos sociais" (PARENTE, 2016, p. 574). Já de acordo com Coelho (2012, p. 81) podem ser elencadas duas justificativas para a ampliação da jornada escolar: "(1) a busca de melhoria na qualidade do ensino, por meio de uma formação mais completa e (2) a proteção à criança em situação de vulnerabilidade social [...]”. 
Conforme mostram as pesquisas sobre educação em tempo integral, historicamente, no contexto brasileiro, optou-se por oferecer às crianças e adolescentes uma educação mínima, no que se refere ao tempo, ao currículo e ao espaço da ação educativa. Mesmo que ainda não haja consensos em relação aos objetivos da educação integral em tempo integral, vimos ao longo da história inúmeras defesas e tentativas de implementá-la, ou seja, foram sendo disseminados vários argumentos para a ampliação do tempo escolar, defendendo-se mais e melhores oportunidades educativas (RIBETTO; MAURÍCIO, 2009).

No município analisado, do ponto de vista documental e com base no relato dos gestores, o argumento preponderante para tal opção foi pedagógico, ou seja, melhoria da qualidade da educação e da escola. No entanto, durante o acompanhamento das oficinas curriculares, ou seja, durante o processo de implementação da jornada escolar em tempo integral, foram visíveis as articulações entre os argumentos pedagógicos e sociais, relacionando qualidade da educação à proteção social.

O fato é que, seja qual for a justificativa ou o argumento da política, a ampliação do tempo escolar, sem a sua articulação a outros aspectos, por si só, não repercutirá na educação integral dos alunos.

Assim, diante de um tempo ampliado, de uma jornada escolar em tempo integral, como a escola parceira se organizou e estabeleceu suas opções político-pedagógicas?

Conforme dados coletados por meio de questionário aplicado aos professores, quando a escola analisada passou a funcionar com jornada em tempo integral, 63\% dos professores já trabalhavam lá. Esse aspecto poderia ser um elemento de grande relevância, caso a opção por se tornar uma escola em tempo integral fosse resultado de um desejo coletivo da equipe da escola, conforme salientado anteriormente. Ou seja, a depender da forma como a escola implementa a jornada em tempo integral, pode haver resistências ao seu projeto, carências nas formas de articulação entre a equipe e até falta de compromisso da equipe com o projeto da escola. Quando a equipe não assume um projeto de escola ou uma política pública específica, ou quando parte dessa equipe se mostra refratária, contrária ou dificulta o trabalho dos demais, certamente haverá dificuldades para a sua consecução.

Conforme $75 \%$ dos professores que responderam ao questionário, quando a escola parceira começou a funcionar em tempo integral, dada a mudança na jornada escolar, seria importante trabalhar de forma diferente do que vinham fazendo. Assim, considerando-se a especificidade de uma escola de tempo integral, para $81 \%$ dos professores é importante que haja uma mudança na postura e na didática dos professores, ou seja, a mudança na jornada escolar deve levar a uma mudança nas práticas docentes. No entanto, é preciso salientar que a mudança de 
práticas pedagógicas depende de uma série de fatores internos e externos ao corpo docente. $\mathrm{E}$ tais mudanças não ocorrem por decretos e nem de um momento para outro.

Para $81 \%$ dos professores que responderam ao questionário, a escola de tempo integral oferece uma formação melhor aos alunos em comparação à escola de tempo parcial e $88 \%$ dos professores acham que a escola em que atuam traz grande contribuição à formação integral dos alunos. No entanto, ainda concebem que essa não é a escola que idealizam em termos de educação integral em tempo integral. Ainda persistem incômodos e dificuldades: $81 \%$ dos professores acreditam que o currículo precisa ser alterado; $88 \%$ concebem que os espaços da escola são insuficientes para o bom desenvolvimento da prática pedagógica e $88 \%$ defendem a existência de mais espaços para a formação continuada.

De acordo com Parente (2006), considera-se que tempo, currículo e espaço são elementos determinantes na organização do trabalho pedagógico (embora, também sejam condicionados). Não são os únicos, mas são extremamente relevantes e devem ser alvo de intensas discussões quando se trata da formulação e da implementação de políticas de educação integral em tempo integral.

No que se refere ao currículo escolar, são várias as questões envolvidas quando se trata de selecionar o que cabe à escola em termos de transmissão/(re)produção dos conhecimentos historicamente acumulados (FORQUIN, 1993). Ou seja, a construção do currículo escolar é um desafio recorrente e imensamente relevante, em se tratando do significado do que venha a ser mais e melhores oportunidades educativas num tempo ampliado.

Em termos de currículo, conforme Parente (2016), é possível categorizar as políticas de educação integral em tempo integral quanto à organização curricular (padronizadas e não padronizadas) e quanto à integração curricular (com currículo integrado e com currículo no formato contraturno). Analisando-se os documentos do município pesquisado, pode-se afirmar que a organização curricular é semi-padronizada, com currículo no formato contraturno.

No que se refere à organização curricular, a escola parceira, conforme destacado anteriormente, pautada na legislação municipal, definiu suas oficinas curriculares. É importante ressaltar que suas opções em termos de organização curricular, respeitadas as determinações legais, conforme relatos dos gestores e análise documental, foram diferentes das opções das outras quatro escolas que também funcionam com jornada em tempo integral no município. Isso ilustra as articulações entre as opções nos âmbitos macro e micro do sistema de ensino. As decisões tomadas no âmbito macro nem sempre são no sentido de padronização; podem ser no sentido de direcionamento e de parâmetro para a ação pedagógica.

\begin{tabular}{l|c|c|c|c|c|c} 
(C) Rev. Educ. Perspec. & Viçosa, $M G$ & v.9 & n.2 & p.330-346 & maio/ago. 2018 & eISSN 2178-8359 \\
\hline
\end{tabular}


Assim, no que se refere aos incômodos relativos ao currículo, destacados por $81 \%$ dos professores no questionário aplicado, alguns apontaram que isso pode ser feito, incorporandose oficinas relacionadas à música, ao esporte, à dança, à cultura. Isto porque é importante que as oficinas ofereçam atividades diferentes do chamado currículo "regular". Outros informaram que isso poderia ser feito por meio de atividades mais dinâmicas no interior das próprias oficinas já existentes e por meio do melhor uso dos recursos e dos espaços da escola. Percebe-se, portanto, que as mudanças indicadas pelos professores, nos questionários, e pelos gestores, nas reuniões realizadas com a escola parceira, poderiam ser feitas no âmbito da própria escola. As oficinas sugeridas estão referenciadas na legislação municipal e o planejamento pedagógico, com a incorporação de atividades mais lúdicas e prazerosas, é uma prerrogativa da própria equipe escolar. Com isso, deseja-se ressaltar que as alterações curriculares não devem ser entendidas apenas como alteração de uma grade de horários/atividades; alterações curriculares compreendem, em grande medida, alterações de concepções e de práticas pedagógicas. No entanto, tais alterações não ocorrem sem resistências.

Em termos de integração curricular, conforme categorizado por Parente (2016), a legislação municipal optou pelo currículo no contraturno; não foi opção da escola o contraturno e esse elemento a priori, condiciona algumas situações visualizadas no processo de implementação da jornada em tempo integral na escola analisada.

Durante os grupos de discussão, os professores relataram incômodos relativos à integração entre os turnos e entre os profissionais que atuam nos dois turnos: manhã e tarde. Isso também foi evidenciado no questionário aplicado: $88 \%$ dos professores informaram que há pouca integração entre os profissionais. Apenas alguns poucos professores atuam nos dois turnos, raras exceções. É crescente, nas escolas de tempo integral, a concepção de que, na parte da manhã, os alunos estudam e que, na parte da tarde, os alunos brincam. Em meio a essa concepção simplista, vêm à tona inúmeras contradições, entre elas: a diferenciação entre as atividades e as práticas pedagógicas nos dois turnos. Para superação das muitas contradições existentes, o horário de estudo coletivo dos profissionais da escola poderia ser um momento importante para discussões, formações, socializações, reconhecimento da equipe, diagnósticos, redefinições curriculares, trocas de experiências etc. São necessárias estratégias coletivas para que, diante da dicotomia dos turnos, a equipe se reconheça como parte de um projeto coletivo de educação integral em tempo integral.

Conforme já explicitado, a legislação municipal, por um lado estabeleceu diretrizes para o currículo das escolas de tempo integral e, por outro, delegou uma parcela de autonomia à escola na definição de suas oficinas. Não sem razão, a equipe escolar escolheu as oficinas curriculares a partir das condições materiais existentes na escola. Ou seja, cada escola precisa definir oficinas que sejam viáveis frente às suas condições materiais.

\begin{tabular}{l|c|c|c|c|c|c} 
(C) Rev. Educ. Perspec. & Viçosa, $M G$ & v.9 & n.2 & p.330-346 & maio/ago. 2018 & eISSN 2178-8359 \\
\hline
\end{tabular}


A materialidade da escola brasileira, historicamente, deu mostras de um processo contínuo de sucateamento. Antigas construções escolares com auditórios, quadras, laboratórios, refeitórios, vestiários, muitas vezes em nome da expansão e da democratização do ensino, foram dando lugar a prédios enxutos, restritos às salas de aula. Políticas com foco em construções foram substituídas por ações restritas a reformas e ampliações, muitas das quais centradas em salas de aula. Esse cenário ilustra a existência de escolas cuja materialidade inibe muitas ações pedagógicas.

$\mathrm{O}$ argumento de que a materialidade da escola e, especificamente, o seu espaço, é fator de grande relevância para o desenvolvimento da ação educativa - ainda mais quando se pensa na ampliação dessa ação e do tempo no espaço educativo - sempre esteve presente nos discursos pedagógicos. Na escola parceira, assim como em muitas outras escolas que possuem jornada escolar em tempo integral, os espaços físicos são um grande desafio.

Conforme destacado anteriormente, $88 \%$ dos professores que responderam ao questionário, indicaram a necessidade de mais espaços para atender melhor as necessidades de alunos e professores. Apesar disso, alguns informaram a importância de explorar mais e melhor os poucos espaços existentes na escola. Concebe-se que qualquer política de educação integral em tempo integral deve dar aos professores condições adequadas de trabalho e, aos alunos, condições adequadas para vivenciarem diferentes oportunidades educativas. No entanto, a existência de mais e melhores espaços educativos não garante mudanças de concepções e práticas pedagógicas.

A sala de aula tem sido o lugar de excelência para o trabalho do professor junto aos alunos. Essa é a prática em muitas escolas. Porém, outros espaços podem ser utilizados para o desenvolvimento da prática pedagógica. Ao acompanhar o cotidiano da escola parceira são visíveis tanto os limites da materialidade (que realmente condicionam o trabalho docente), como as resistências dos professores em fazerem uso dos espaços disponíveis para além da sala de aula, ainda que sejam poucos. Mais uma vez vale destacar que mudanças na prática pedagógica não ocorrem por decreto. Numa escola que funciona com jornada em tempo integral, limitar as ações educativas à sala de aula inibe um projeto de educação integral que, entre outros elementos, possa ampliar os movimentos, as ações e as oportunidades.

Diante desse quadro relacionado à materialidade das escolas de tempo integral, têm surgido muitas políticas de educação integral em tempo integral que desenvolvem ações em espaços escolares e não escolares, bem como políticas de educação integral em tempo integral que estabelecem relações público-privadas e intersetoriais (PARENTE, 2016), muitas vezes, como complementação dos recursos e espaços públicos. Na escola analisada, embora existam intencionalidades da equipe gestora de fazer uso dessas possibilidades, isso ainda não se materializou. 
No que se refere aos recursos humanos, conforme Parente (2016), quanto à formação dos responsáveis pela ação educativa, as políticas de educação integral em tempo integral podem ser implementadas por profissionais da educação e/ou por diferentes profissionais. Quanto ao vínculo profissional, as políticas de educação integral em tempo integral podem ser implementadas por profissionais concursados e/ou com diferentes vínculos profissionais.

Conforme dados fornecidos pela equipe gestora da escola parceira, a maioria dos profissionais é efetiva na rede municipal, com formação em Pedagogia, atendendo ao que determina a legislação municipal, conforme destacado anteriormente. Essa configuração, em termos de formação e de vínculo, apresenta aspectos positivos no que concerne à opção político-pedagógica da Secretaria de Educação analisada, em contraposição a muitas políticas que vêm aderindo à contratação de profissionais e à seleção de voluntários para oferta das atividades de ampliação da jornada escolar - a exemplo do Programa Mais Educação do governo federal, conforme descreve Parente (2017).

No entanto, é preciso enfatizar que essa configuração em termos de formação e de vínculo profissional também tem seus limites num projeto de educação em tempo integral que preze pela diversificação do currículo e de oportunidades educativas que levem a uma formação integral dos alunos. Essa configuração, de certa forma, engessa as escolhas das oficinas de enriquecimento curricular e, muitas vezes, a escola acaba escolhendo oficinas que não destoem muito do que a escola já vem trabalhando e do que comumente os profissionais sabem fazer e vêm fazendo. Apesar disso, há possibilidades de ultrapassar esses limites por meio do planejamento pedagógico coletivo e da formação continuada. Porém, isso vai depender de como a equipe escolar se organiza diante de seu projeto de escola de tempo integral e de uma série de fatores internos e externos a ela.

Durante o acompanhamento da implementação da jornada em tempo integral e por meio dos relatos feitos pela equipe gestora, houve indicações de que a escola parceira caminha para pequenas alterações curriculares, por um lado, atendendo a algumas demandas dos professores, por outro, atendendo aos próprios anseios da equipe gestora. No entanto, como já apontado, a materialidade da escola impede alterações significativas, tendo em vista a necessidade de reforma e de ampliação dos espaços hoje existentes. Apesar disso, a alteração curricular não pode ficar dissociada do compromisso docente com essa nova organização do trabalho pedagógico. As resistências em relação às mudanças nas práticas pedagógicas persistem.

Por fim, o acompanhamento da escola parceira trouxe à tona a necessidade de espaços formativos para a discussão de aspectos relacionados à atuação docente numa escola de tempo integral. Conforme destacado anteriormente, $88 \%$ dos professores que responderam ao questionário, destacaram a importância da existência de mais espaços formativos. Sobre esse

\begin{tabular}{|c|c|c|c|c|c|c|} 
(C) Rev. Educ. Perspec. & Viçosa, $M G$ & v.9 & n.2 & p.330-346 & maio/ago. 2018 & eISSN 2178-8359 \\
\hline
\end{tabular}


aspecto, salienta-se a inexistência de uma ação institucional coordenada pela Secretaria Municipal de Educação em relação às escolas que atualmente funcionam em tempo integral. O único espaço de formação existente são os horários de estudos coletivos no âmbito de cada escola, o que oferece margem para que cada estabelecimento de ensino faça suas próprias opções político-pedagógicas no campo da formação continuada de professores.

Assim, pode-se dizer que tem sido uma opção político-pedagógica da Secretaria Municipal de Educação deixar a cargo das escolas, nos horários de estudos coletivos, a responsabilidade por definir temáticas e ações de formação, o que pode ser importante em termos de autonomia, mas também um risco, caso não seja feito um adequado diagnóstico de necessidades e interesses formativos. No âmbito da escola parceira, o presente Projeto cumpriu, minimamente, esse papel; atendeu, em parte, algumas das demandas dos professores e da equipe gestora, no que se refere às necessidades formativas de uma escola de tempo integral, fortalecendo a ideia de que as questões tratadas neste artigo são essenciais.

Diante das análises aqui expostas sobre como ocorre o processo de construção de uma escola de tempo integral e sobre as relações entre as opções político-pedagógicas definidas no âmbito da Secretaria Municipal de Educação e as opções político-pedagógicas definidas no âmbito da escola, defende-se que

\begin{abstract}
Se, por um lado, é na escola onde ocorrem as inovações educacionais, por outro é a própria política que possibilita, em grande medida, que as condições materiais para as inovações se estabeleçam. É, certamente, via de mão dupla: uma política que cria condições para inovações; uma escola que inova, ao aderir a uma política inovadora. E mesmo uma escola inovadora que impulsiona a formulação de uma política e uma política que inova justamente porque aderiu a inovações escolares (PARENTE, 2006, p. 11).
\end{abstract}

Assim, é importante que os gestores que atuam na área educacional, seja no nível macro ou no nível micro, compreendam a multidirecionalidade e a multidimensionalidade do processo decisório na formulação e na implementação das políticas de educação em tempo integral. E para isso é imprescindível investir no acompanhamento sistemático das escolas, de seus projetos, de seus problemas, experiências, necessidades, dificuldades e inovações; e ainda, envolver diferentes atores no processo de formulação das políticas educacionais.

\title{
CONSIDERAÇÕES FINAIS
}

O presente trabalho buscou responder ao questionamento principal: diante de uma política de educação integral em tempo integral, como se constrói uma escola de tempo integral? Para responder a esse questionamento o artigo analisou o processo de construção de uma escola de tempo integral no interior de São Paulo, sistematizando as relações entre as opções político-

\begin{tabular}{l|l|l|l|l|l|l} 
(C) Rev. Educ. Perspec. & Viçosa, $M G$ & v.9 & n.2 & p.330-346 & maio/ago. 2018 & eISSN 2178-8359 \\
\hline
\end{tabular}


pedagógicas definidas no âmbito da Secretaria Municipal de Educação (macro) e as opções político-pedagógicas definidas no âmbito da escola (micro).

Durante a exposição deste trabalho buscou-se evidenciar as concepções de política e de escola e suas muitas articulações, destacando a multidirecionalidade da política e, portanto, a relevância das ações que são desenvolvidas no âmbito da escola, a fim de ultrapassar visões racionalistas e unidirecionais que reduzem o processo de tomada de decisão ao "cumpra-se".

Ainda que se tenha clareza dos muitos determinantes e condicionantes da instituição escolar, partiu-se do pressuposto principal de que a escola não pode ser vista como mera instituição reprodutora das definições estabelecidas no âmbito macro do sistema de ensino. Seus sujeitos, também atores nos cenários das mais diferentes políticas educacionais, são também, em certa medida, (re)formuladores da política pública.

O cenário educacional atual vem propiciando a disseminação de políticas de educação integral em tempo integral. É, portanto, momento importante para desencadear discussões e formações acerca da temática. Mais ainda, é importante disseminar novas formas de aproximação das diferentes experiências que estão surgindo, captando suas características, suas dificuldades e suas inovações sob os mais diferentes ângulos.

O município e a escola parceira são experiências únicas entre tantas outras que estão sendo desenvolvidas pelo país afora. Nesse exercício, evidenciou-se que são muitos os elementos que podem fortalecer e/ou enfraquecer a construção de políticas e de escolas de tempo integral. A cada experiência surgem novos elementos e novas articulações para entender melhor o processo de decisão política. É imprescindível buscar compreender quais são esses elementos, como se constituem, como surgem, como se articulam, de onde partem e como podem ser explicados.

Diante do exposto, e para além do objetivo deste artigo questiona-se: as mudanças que cabem à Secretaria de Educação estão sendo feitas? Estão sendo decididas com base em quê? Quem participa dessas decisões? Em que medida o processo de implementação da política no âmbito das escolas tem oferecido subsídios aos gestores municipais para uma (re)formulação da política pública de educação em tempo integral? Por outro lado, as mudanças que cabem à equipe escolar estão sendo feitas? Como estão sendo decididas e por quem?

Questões como essas e muitas outras precisam ser formuladas e consideradas para fins de análise da política pública, a fim de que não sejam feitas avaliações simplistas de políticas educacionais e de seus resultados, responsabilizando esses ou aqueles atores/processos (em detrimento de outros) por sucessos e/ou fracassos na área da educação, sem uma discussão profunda dos mais diferentes aspectos que incidem nos processos decisórios.

\begin{tabular}{l|c|c|c|c|c|c} 
(C) Rev. Educ. Perspec. & Viçosa, $M G$ & v.9 & n.2 & p.330-346 & maio/ago. 2018 & eISSN 2178-8359 \\
\hline
\end{tabular}




\section{REFERÊNCIAS}

BRASIL. Lei n. 9.394, de 20 de dezembro de 1996. Disponível em:

http://www.planalto.gov.br/ccivil_03/leis/L9394.htm. Acesso em: 10 abr. 2017.

BRASIL. Decreto no 6.253, de 13 de novembro de 2007. Dispõe sobre o Fundo de Manutenção e Desenvolvimento da Educação Básica e de Valorização dos Profissionais da Educação - FUNDEB, regulamenta a Lei n 11.494, de 20 de junho de 2007, e dá outras providências. 2007. Disponível em: http://www.planalto.gov.br/ccivil_03/_ato20072010/2007/decreto/D6253.html. Acesso em: 10 abr. 2017.

BRASIL. Lei n. 13.005, de 25 de junho de 2014. Disponível em: https://www.planalto.gov.br/ccivil_03/_ato2011-2014/2014/lei/113005.htm. Acesso em: 10 abr. 2017.

COELHO, Lígia Martha Coimbra da Costa. Alunos no ensino fundamental, ampliação da jornada escolar e Educação Integral. Educação em Revista, Curitiba, n. 45, p. 73-89, jul./set. 2012.

DIAS, Reinaldo; MATOS, Fernanda. Políticas públicas: princípios, propósitos e processos. São Paulo: Editora Atlas, 2012. 264p.

DOMINGUES, Isaneide. Grupos dialogais: compreendendo os limites entre pesquisa e formação. In: PIMENTA, Selma Garrido; GHEDIN, Evandro; FRANCO, Maria Amélia Santoro (Org.). Pesquisa em educação: alternativas investigativas com objetos complexos. São Paulo: Edições Loyola, 1. ed., 2006. P. 165-182.

DRAIBE, Sonia Miriam. Metodologia de análise comparativa de programas sociais. 1991. Disponível em: http://repositorio.cepal.org/bitstream/handle/11362/33735/ S9100594_es.pdf?sequence=1. Acesso em: 10 abr. 2017.

FALKEMBACH, Elza Maria Fonseca. Diário de campo: um instrumento de reflexão. Contexto e Educação, Ijuí, v. 2, n. 7, p. 19-24, jul./set. 1987.

FORQUIN, Jean-Claude. Escola e cultura: as bases sociais e epistemológicas do conhecimento escolar. Trad. Guacira Lopes Louro. Porto Alegre: Artes Médicas, 1993. 208p.

HÖFLING, Heloisa de Matos. Estado e políticas (públicas) sociais. Cadernos Cedes, Campinas, v. 21, n. 55, p. 30-41, nov. 2001.

LIMA, Licínio C. A escola como organização educativa. São Paulo: Cortez, 2011. 208p.

LINDBLON, Charles Edward. O processo de decisão política. Brasília, DF: UNB, 1981. $124 \mathrm{p}$.

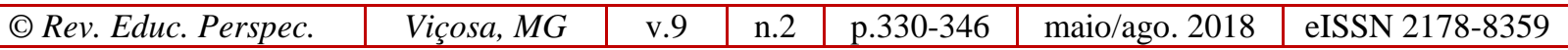


SILVA, Pedro Luiz Barros; MELO, Marcus André Barreto de. O processo de implementação de políticas públicas no Brasil: características e determinantes da avaliação de programas e projetos. Caderno NEPP/UNICAMP, Campinas, n. 48, p. 1-16, 2000.

NÓVOA, António. As organizações escolares em análise. Portugal: Dom Quixote, 1999. $188 \mathrm{p}$.

PARENTE, Cláudia da Mota Darós. A construção dos tempos escolares: possibilidades e alternativas plurais. 2006. 173f. Tese (Doutorado em Educação) - Universidade Estadual de Campinas, Faculdade de Educação, Campinas, 2006.

PARENTE, Cláudia da Mota Darós. Construindo uma Tipologia das Políticas de Educação Integral em Tempo Integral. Roteiro, Joaçaba, v. 41, n. 3, p. 563-586, set./dez. 2016.

PARENTE, Cláudia da Mota Darós. Programa Mais Educação: impactos e perspectivas nas escolas do campo. Revista Eletrônica de Educação, São Carlos, v. 11, n. 2, p. 439-454, jun./ago. 2017.

PETITAT, André. Produção da escola, produção da sociedade: análise sócio-histórica de alguns momentos decisivos da evolução escolar no ocidente. Porto Alegre: Artes Médicas, 1994. 268p.

RIBETTO, Anelice; MAURÍCIO, Lúcia Velloso. Duas décadas de educação em tempo integral: dissertações, teses, artigos e capítulos de livros. Em Aberto, Brasília, v. 22, n. 80, p. 137-160, abr. 2009.

\section{NOTAS}

i O artigo é resultado das reflexões produzidas por meio do Projeto "Encontros de formação: limites e possibilidades de ampliação da jornada escolar" e, especificamente, por meio do Projeto "Planejamento e Organização do Trabalho Pedagógico em Escolas de Tempo Integral". Este último projeto teve como objetivo acompanhar e orientar o processo de planejamento e organização do trabalho pedagógico de uma escola em tempo integral. Projetos financiados com recursos do Núcleo de Ensino da Pró-Reitoria de Graduação UNESP.

ii Foram coletados e analisados documentos legais do município e da escola. Porém, não serão citados ou referenciados documentos que possam fazer menção à identidade do município e da escola.

iii Adotamos perspectiva similar ao grupo dialogal desenvolvido por Domingues (2006).

${ }^{\text {iv }} \mathrm{O}$ diário de campo é um recurso de registro de dados de pesquisa, conforme Falkembach (1987).

v A política pública não é estática e, portanto, tais características são sempre específicas de determinado momento e contexto político e histórico.

\section{Sobre a Autora}

${ }^{1}$ Cláudia da Mota Darós Parente - Professora da Universidade Estadual Paulista. E-mail: claudiadaros@marilia.unesp.br - ORCID: https://orcid.org/0000-0003-0250-8935

\begin{tabular}{l|c|c|c|c|c|c} 
(C) Rev. Educ. Perspec. & Viçosa, $M G$ & v.9 & n.2 & p.330-346 & maio/ago. 2018 & eISSN 2178-8359 \\
\hline
\end{tabular}

